\section{Risk behaviors for eating disorders and depressive symptoms: a study of female adolescents in Juiz de Fora, Minas Gerais State, Brazil}

\author{
Comportamentos de risco para transtornos \\ alimentares e sintomas depressivos: um estudo \\ com jovens do sexo feminino de Juiz de Fora, \\ Minas Gerais, Brasil
}

\author{
Comportamientos de riesgo en trastornos \\ alimentarios y síntomas depresivos: un estudio \\ de mujeres jóvenes de Juiz de Fora, Minas \\ Gerais, Brasil
}

\begin{abstract}
The objective of this study was to analyze the relationship between depressive symptoms and eating disorders in female adolescents. The sample included 371 girls ranging from 12 to 16 years of age in Juiz de Fora, Minas Gerais State, Brazil. The study used the Eating Attitudes Test (EAT-26) and Major Depression Inventory (MDI) to evaluate eating disorders and depressive symptoms, respectively. The linear regression model showed that 18\% of the EAT-26 scores were influenced by $\operatorname{MDI}(F(1,370)=14.18 ; p=0.001)$. Moreover, the findings indicated a statistically significant association between depressive symptoms and eating disorders $\left(\chi^{2}=14.71 ;\right.$ Wald $=12.90 ; p=$ 0.001). The authors concluded that depressive symptoms were related to eating disorders in female adolescents. Thus, girls with some level of depression showed a greater tendency to adopt disordered eating as a daily habit.
\end{abstract}

Eating Disorders; Depression; Adolescent
Leonardo de Sousa Fortes 1,2 Juliana Fernandes Filgueiras 2 Maria Elisa Caputo Ferreira ${ }^{2}$

\section{Resumo}

O objetivo foi analisar a relação dos sintomas depressivos com os comportamentos de risco para transtornos alimentares em adolescentes do sexo feminino. Participaram 371 jovens com idade entre 12 e 16 anos de Juiz de Fora, Minas Gerais, Brasil. Utilizaram-se o Eating Attitudes Test (EAT-26) e o Major Depression Inventory (MDI) para avaliar os comportamentos de risco para transtornos alimentares e os sintomas depressivos, respectivamente. $O$ modelo de regressão linear evidenciou que $18 \%$ dos scores do EAT26 foram influenciados pelo $\operatorname{MDI}(F(1,370)=$ 14,18; $p=0,001)$. Ademais, os achados indicaram associação estatisticamente significativa entre os sintomas depressivos e os comportamentos de risco para transtornos alimentares $\left(\chi^{2}=\right.$ 14,71; Wald =12,90; $p=0,001$ ). Concluiu-se que os sintomas depressivos estiveram relacionados aos comportamentos de risco para transtornos alimentares em adolescentes do sexo feminino. Logo, as jovens com algum nível de depressão demonstraram maior tendência em adotarem os comportamentos de risco para transtornos alimentares como hábito cotidiano.

Transtornos Alimentares; Depressão; Adolescente 


\section{Introduction}

Self-induced vomiting, food restriction, and use of laxatives and/or diuretics are some examples of risk behaviors for eating disorders 1 . Risk behaviors for eating disorders are considered harmful to health 2,3. Evidence suggests prevalence of risk behaviors for eating disorders ranging from $15 \%$ to $25 \%$ of the world population 4,5 , and this prevalence appears to be higher in adolescents 1,6, especially in girls 7,8 .

According to the World Health Organization (WHO) 9, adolescence includes the phase from 10 to 19 years of age, during which young girls undergo various psychological and physical changes 6 . Several biological and hereditary factors can be associated with risk behaviors for eating disorders in adolescents. Biological factors include genetic coding and the serotoninergic system 2,4 . Thus, young people with given genes and/or elevated serotonin secretion can be vulnerable to risk behaviors for eating disorders. Hereditary factors include parents that adopt daily risk behaviors for eating disorders 5 . In this sense, daughters of parents with risk behaviors for eating disorders are themselves susceptible to the adoption of risk behaviors for eating disorders. Cultural factors can also bear a close relationship to risk behaviors for eating disorders. The mass media have emphasized thinness as a morphological characteristic associated with social acceptance 10 . Thus, the female gender usually extols physical appearance oriented towards thinness, while for many girls this body aesthetic is unattainable 12 . Studies indicate that the pursuit of an ideal body appears to affect adolescent girls more readily than boys, as they pursue the body shape imposed by the mass communications media (TV, magazines, and cinema) 5,13 , leading to body dissatisfaction ${ }^{10}$. Authors recommend statistically controlling the level of body dissatisfaction in studies aimed at relating risk behaviors for eating disorders to other factors. However, failure to reduce weight and reach a slim aesthetic appearance can leave adolescent girls vulnerable to depression.

Depression, in turn, is an altered state of mood involving sadness, loss of the capacity to feel pleasure, and cognitive, motor, and somatic alterations; such factors can interfere in the individual's social functioning 14,15. According to Schulte \& Thomas ${ }^{3}$, depression can be related to risk behaviors for eating disorders. The authors suggest depressive symptoms as possible predictors of risk behaviors for eating disorders. Despite empirical evidence of the relationship between depressive symptoms and risk behaviors for eating disorders 3,4 , a search of some descriptors ("depression", "eating disorders", and "eating behaviors") in the main sites for scientific articles (SciELO, Scopus, Web of Science, and MEDLINE) failed to identify any such studies of Brazilian adolescent girls. This gap highlights the need to develop such a study in this population group. Given the above, the current study aimed to analyze the relationship between depressive symptoms and risk behaviors for eating disorders in female adolescents.

The following hypotheses were thus proposed: (1) depressive symptoms bear a positive relationship to risk behaviors for eating disorders in female adolescents; (2) girls with depressive symptoms are more susceptible to risk behaviors for eating disorders; and (3) body dissatisfaction is related directly to depressive symptoms and risk behaviors for eating disorders in female adolescents.

\section{Methods}

\section{Participants}

This was a cross-sectional school-based study conducted in the year 2012 in the city of Juiz de Fora, Minas Gerais State, Brazil, with female adolescents between 12 and 16 years of age.

According to the Juiz de Fora Department of Education, there were approximately 35 thousand female adolescents from 12 to 16 years of age enrolled in the municipal school system. A sample was thus calculated using the following criteria, following recommendations by Alves et al. 1: $30 \%$ prevalence of risk behaviors for eating disorders according to findings by Scherer et al. 7 and Martins et al. 8, 95\% confidence interval, 5\% sampling error, and 1.4 for design effect, totaling 318 schoolchildren for evaluation in order to obtain an adequate sample to conduct statistical analyses.

The proportional sample was stratified according to enrollment in the schools in the various subdivisions of the municipality of Juiz de Fora (north, south, and center) and school administration modality (public versus private) Next, the sample was divided into primary and middle school students. Random selection used simple two-stage sampling. First the schools were selected in each region, and next the adolescents were selected in the schools. The schools were selected from a list provided by the statistics division of the Minas Gerais State Department of Education. The final study sample was distributed in six different data collection points (schools) and consisted of randomly selected female adolescents who were attending school on the data collection days. 
The study only included girls regularly enrolled in primary or middle school in the city of Juiz de Fora in the year 2012. The eligible study population thus consisted of 389 girls.

\section{Instruments}

Evaluation of risk behaviors for eating disorders used the Eating Attitudes Test (EAT-26), validated for Brazilian adolescent girls by Bighetti et al. 16 . The questionnaire consists of 26 questions that aim to assess pathological refusal to eat highcalorie foods, preoccupation with physical appearance, episodes of binge eating, purging behaviors for weight loss or control, self-control in relation to food, and environmental and social forces that encourage food intake. The subject has six options for answering each item varying from 0 (seldom, almost never, and never) to 3 (always). The only question scored in reverse order is number 25. The EAT-26 score is the sum of its items. A total score greater than or equal to 21 is considered positive for eating disorder (EAT+). In the validation study, Bighetti et al. 16 showed internal consistency of 0.82 . The current sample showed internal consistency of 0.87 , as assessed by Cronbach's alpha.

Depressive symptoms were assessed by the Major Depression Inventory (MDI), translated and adapted to the Portuguese language by Parcias et al. 14. MDI includes the 10 symptoms of depression from the 10th revision of the International Classification of Diseases (ICD-10) 17, besides assessing the severity of depressive symptoms. MDI is classified as a short screening instrument and can be applied in different research and mental health contexts. Items 8 and 10 of MDI have subitems "a" and "b", considering higher scores for them. Higher scores mean greater magnitude of depressive symptoms. Scores can vary from 0 to 50 , and 16 or more indicates risk of depression (MDI+). The cross-cultural adaptation study for MDI 14 identified internal consistency of 0.91 . The current study showed Cronbach's alpha of 0.89 , representing good internal consistency.

Body dissatisfaction was assessed with the Body Shape Questionnaire (BSQ). BSQ is a selfcompleted instrument with 34 questions in a Likert-type scale format, with points ranging from 1 (never) to 6 (always), aimed at assessing the frequency of the girl's preoccupation or discontent with her weight and physical appearance, that is, her body dissatisfaction. Higher scores mean the individual's greater self-depreciation of body shape. The final score on BSQ further allows categorization as: $<80$ (no body dissatisfaction), $\geq$ 80 and $<110$ (mild dissatisfaction); $\geq 110$ and $<$ 140 (moderate dissatisfaction); and $\geq 140$ (severe body dissatisfaction). The questionnaire was validated for the Brazilian adolescent population 18 and displayed good psychometric properties. Internal consistency for the present sample was calculated by Cronbach's alpha, obtaining a satisfactory value of 0.96 . Considering that body dissatisfaction can influence risk behaviors for eating disorders 7, the choice was made to control the BSQ scores in some of the data analyses.

Body mass was measured with a portable digital scale (Tanita model BC-601, São Paulo, Brazil), accurate to $100 \mathrm{~g}$ and with a maximum capacity of $200 \mathrm{~kg}$. A portable stadiometer was used, accurate to $0.1 \mathrm{~cm}$ and with a maximum height of $2.20 \mathrm{~m}$ (Welmy model et-276; Santa Bárbara do Oeste, Brazil) to measure the adolescents' height. Next, body mass index $[\mathrm{BMI}=$ body mass $(\mathrm{kg}) /$ height $\left.\left(\mathrm{m}^{2}\right)\right]$ was calculated. BMI z-score was used as the indicator of nutritional status. Classification of the BMI z-score followed WHO guidelines 9 , with classification as underweight, normal weight, overweight, and obese according to $\mathrm{z}$-scores $(-2$, +1 , and +2 ) as a function of chronological age. Since scientific evidence shows a relationship between BMI and risk behaviors for eating disorders 5,7 , the decision was made to control BMI in some of the statistical analyses.

\section{Procedures}

The principals of ten schools (five private and five public) were invited to participate in the study and were informed of the objectives and procedures. However, only six principals (three private and three public) agreed to allow their students to participate in the study. After authorization by the schools' administrations, meetings were held with each of the classes to explain the objectives and procedures needed to include the schoolchildren in the study. A free and informed consent form was given to the adolescents, and they were asked to return it properly signed by their parents or guardians the following week if the latter agreed to their voluntary participation. The participants themselves also signed an informed consent form agreeing to participate in the study.

The study was conducted in two stages. First the students answered the instruments (EAT-26, MDI, and BSQ). This stage was conducted in groups led by a single researcher, who standardized the verbal explanations. Next, the students were led to another room, barefoot and wearing physical education uniforms. In this second stage, anthropometric measurements were taken individually, and only one student was allowed to enter each time.

The study was approved by the Ethics Research Committee of the Federal University of 
Juiz de Fora (case review 2282.022.2011) in accordance with Resolution n. 196/96 of the Brazilian National Health Council.

\section{Statistical analysis}

The Kolmogorov Smirnov test was performed to assess distribution of the dependent variable (EAT-26). Due to parametric non-violation, the study used measures of central tendency (mean), dispersion (standard deviation, standard error, minimum, and maximum) and relative frequency to describe the target variables. Simple linear regression was used to evaluate the relationship between MDI and the EAT-26 scores, controlling for the BSQ scores. This same test was used to analyze the relationship between the BSQ scores and MDI and EAT-26. Binary logistic regression was also used to analyze the association between the dichotomous classifications of MDI and EAT-26. Univariate analysis of covariance (ANCOVA) was used to compare the EAT-26 scores as a function of the dichotomous classifications of MDI. This same test was conducted to compare EAT-26 and MDI scores for classifications of nutritional status. The Bonferroni post-hoc test was used to identify possible differences between the groups. Finally, the effect size was calculated, represented by " $d$ " to highlight the practical importance of the differences. Importantly, in all the analyses the BSQ and/or BMI scores were controlled. All the data were treated with SPSS 17.0 (SPSS Inc., Chicago, USA), with significance set at $5 \%$.

\section{Results}

Of the population of 389 girls considered eligible for the study, 18 (4.62\%) declined to answer the questionnaires, leaving a final study sample of 371 adolescent girls.
The results showed that $21.7 \%$ and $20.3 \%$ of the adolescents displayed risk behaviors for eating disorders (EAT+) and depressive symptoms (MDI+), respectively. Prevalence of overweight/ obesity was $28 \%$. Table 1 shows the descriptive data for all the variables.

Linear regression showed that $18 \%$ of the EAT-26 scores were influenced by the MDI $(F(1.370)=14.18 ; \mathrm{p}=0.001)$. In addition, BSQ explained $24 \%$ and $41 \%$ of the scores for MDI $(F(1$. $370)=17.02 ; \mathrm{p}=0.01)$ and EAT-26 $(F(1.370)=$ 64.95; $\mathrm{p}=0.001$ ), respectively.

Meanwhile, logistic regression pointed to a statistically significant association between depressive symptoms (MDI+) and risk behaviors for eating disorders (EAT +$)\left(\chi^{2}=14.71\right.$; Wald $=12.90$; $\mathrm{p}=0.001)$. Girls with MDI scores of 16 or greater showed 1.16 times the odds of risk behaviors for eating disorders (EAT+) compared to those with lower scores.

ANCOVA showed a statistically significant difference in the EAT-26 scores as a function of MDI classification $(F(1.369)=13.60 ; \mathrm{p}=0.01$; $\mathrm{d}=0.5$ ). Girls with depressive symptoms (MDI+) showed a higher frequency of risk behaviors for eating disorders when compared to those with MDI less than 16.

The findings pointed to differences in EAT-26 scores as a function of nutritional status $(F(3$. $367)=29.45 ; \mathrm{p}=0.001 ; \mathrm{d}=0.6$ ). Overweight and obese adolescent girls showed higher frequency of risk behaviors for eating disorders when compared to normal weight and underweight girls. Likewise, ANCOVA indicated differences in MDI scores as a function of nutritional status $(F(3.367)=19.33 ; \mathrm{p}=0.01 ; \mathrm{d}=0.5)$. Overweight and obese girls showed higher frequency of risk behaviors for eating disorders compared to normal weight and underweight girls.

Table 1

Descriptive values for the study variables.

\begin{tabular}{lcccc}
\hline Variable & Minimum & Maximum & Mean & SD \\
\hline EAT-26 & 0 & 54 & 13.33 & 11.68 \\
MDI & 0 & 45 & 10.52 & 10.15 \\
BSO & 34 & 186 & 65.26 & 33.36 \\
BMI & 13 & 36 & 19.23 & 2.89 \\
Age (years) & 12 & 16 & 13.03 & 1.59 \\
\hline
\end{tabular}

BMI: body mass index; BSQ: Body Shape Questionnaire; EAT-26: Eating Attitudes Test; MDI: Major Depression Inventory

SD: standard deviation. 


\section{Discussion}

The study's objective was to analyze the relationship between depressive symptoms and risk behaviors for eating disorders in female adolescents. Some authors have suggested that depressive symptoms can induce harmful health behaviors 3 (self-induced vomiting, use of laxatives/ diuretics, and extenuating physical exercise). In this sense, risk behaviors for eating disorders could be associated with depressive symptoms. The current study's findings generally showed that depressive symptoms were related to risk behaviors for eating disorders in female adolescents, in agreement with the study's hypotheses.

Prevalence of risk behaviors for eating disorders in female adolescents has increased 3. Brazilian studies in recent years have found prevalence rates varying from $20 \%$ to $30 \%$ $7,8,19,20$, corroborating the current study's results. Researchers have suggested that the media may be largely responsible for this situation 5,10. Evidence shows that the desire to lose weight and to adjust to socially accepted morphological patterns leads girls to adopt some risk behaviors for eating disorders 6,13. Although cultural aspects have been highlighted in studies on risk behaviors for eating disorders 5,13 , other factors may also generate susceptibility to such behaviors in adolescents. These include genetic coding, the serotoninergic system, and parents with risks for eating disorders.

Studies show that prevalence of depressive symptoms has increased in the female population 21,22. Findings point to prevalence around $15 \% 3,15$, close to the figure found in this study. The only study that used MDI as an instrument to evaluate depressive symptoms in adolescents 23 showed a prevalence of $31 \%$. Meanwhile, depressive symptoms have been strongly associated with various factors such as obesity 21 , genetic coding 23 , family trauma 24 , quality of life 25 , and body dissatisfaction 21 .

Feelings of discouragement, low self-confidence, sadness, and lack of appetite are considered some of the symptoms of depression 14 . Such feelings appear to induce the adoption of risk behaviors for eating disorders 3 . The current study in fact showed that $18 \%$ of the variance in risk behaviors for eating disorders was explained by depressive symptoms. Thus, adolescents that regularly experience depressed feelings can adopt risk behaviors for eating disorders as an alternative in the search to diminish their depressive symptoms. However, although adolescent girls may reduce these feelings after episodes of risk behaviors for eating disorders, the latter can also have harmful health effects, such as decreased growth hormone secretion, reduced bone mineral density, and cardiovascular problems 2.

Another important point for discussion is the possible interpretation of an item in EAT-26, specifically question 23 ("I engage in dieting behavior"). Considering that the most frequent response has been to item 23 and that "dieting" does not necessarily refer to the typical food restriction involved in some eating disorders, the relationship between depressive symptoms and risk behaviors for eating disorders should be interpreted with caution. Diets are now extremely popular, and each young person may have a different understanding of "diet". In this sense, adolescent girls diet epidemically. Furthermore, the media sells "dieting" as a way of achieving "wellbeing and self-esteem".

Risk behaviors for eating disorders also have a multifactor etiology. Thus, other aspects beyond depressive symptoms may relate to risk behaviors for eating disorders in female adolescents, for example, interpersonal aspects (perfectionism and self-esteem) ${ }^{10}$, morphological aspects (BMI and body fat) ${ }^{8}$, and socio-demographic aspects (ethnicity and gender) 5 . Evidence has shown repeatedly that young people with overweight/obesity are more prone to risk behaviors for eating disorders 8,26 . Nearly $30 \%$ of the adolescent girls in the current study were overweight or obese, which can be considered a public health problem according to some authors 8 . The study also showed higher frequency of risk behaviors for eating disorders among adolescent girls with overweight/obesity, corroborating other studies 8,26 . The girls with excess body fat thus appear to adopt food restriction, self-induced vomiting, and purging with the aim of losing weight and fitting into socially established aesthetic norms 10,12 .

The study showed a statistically significant relationship between body dissatisfaction and depressive symptoms. Other scientific evidence corroborates this finding 3,15. Preoccupation with weight and physical appearance can lead to feelings of discouragement, low self-esteem, and sadness. Likewise, the current study pointed to a statistically significant relationship between body dissatisfaction and risk behaviors for eating disorders. Thus, preoccupation with weight and physical appearance appears to leave adolescent girls more prone to the adoption of food restriction and purging behaviors such as self-induced vomiting and the use of laxatives/diuretics, as demonstrated in other studies 1,5,8,20,26.

Evidence suggests that females are more affected by depressive symptoms when compared to males 21,22. According to Almeida et al. 21, 
individuals with heavy levels of depression tend to display a high frequency of risk behaviors for eating disorders. In addition, the scientific literature has discussed the susceptibility of adolescent girls to the adoption of risk behaviors for eating disorders as a function of emotional status 3 . Depressed adolescent girls may use risk behaviors for eating disorders as a strategy to cope with negative feelings. Corroborating this reasoning, the results showed that adolescent girls with some level of depression (MDI+) showed 1.16 higher odds of using risk behaviors for eating disorders when compared to those with lower frequency of depressive symptoms. In addition, the ANCOVA findings indicated that girls with some level of depression (MDI+) displayed greater frequency of risk behaviors for eating disorders when compared to those with MDI scores less than 16. Risk behaviors for eating disorders may be coping strategies that some girls use to reduce their stress levels, specifically depressive feelings. Considering that many adolescent girls experience situations in their lives that make them more susceptible to depressive symptoms 3 , some may use various strategies to cope with the stressor 26 , namely listening to music, creating optimistic thoughts, or using behaviors to lose weight, for example risk behaviors for eating disorders. Still, scientific research is needed to determine whether adolescents in fact use risk behaviors for eating disorders as coping strategies to mitigate negative feelings.

Although the current study found relevant results for the scientific literature, it also presented some limitations that merit discussion. The main limitation was the use of self-reported evaluation instruments. Researchers have highlighted that individuals may not respond to questionnaires reliably, since the answers are subjective and open to manipulation 26. Meanwhile, Miranda et al. 12 emphasize that in studies with large samples, data collection with easily applicable tools such as questionnaires may be the most feasible method. In addition, the MDI was not validated for this study's target population, which represents an important limitation. However, the instrument's high internal consistency among the adolescents participating in the study (Cronbach's alpha $=0.89$ ) suggests the scale's good psychometric quality in this population. Another limitation was the cross-sectional design, making it impossible to draw causal inference. This means that there is no way to assess the degree of intensity and direction of the observed associations between the study outcome and the independent variable. However, since this was the first study to evaluate the relationship between depressive symptoms and risk behaviors for eating disorders among Brazilian adolescent girls, we believe that that results cover part of the knowledge gap in this area and thus merit discussion in future studies.

The findings allow concluding that depressive symptoms were related to risk behaviors for eating disorders in this sample of female adolescents. That is, female adolescents with depressive symptoms displayed a higher tendency to adopt risk behaviors for eating disorders.

We suggest that preventive counseling programs be implemented in the school system in the city of Juiz de Fora in order to decrease the prevalence of negative feelings and indirectly reduce the frequency of risk behaviors for eating disorders used by adolescent girls. In addition, screened adolescents that present risks for depression or eating disorders could be referred to psychiatric support services.

Finally, we recommend studies to identify other factors potentially related to risk behaviors for eating disorders, as well as including male adolescents in future studies. 


\section{Resumen}

El objetivo fue analizar la relación entre síntomas depresivos con trastornos de la conducta alimentaria en mujeres adolescentes. Participaron 371 jóvenes de edades comprendidas entre 12 y 16 años de Juiz de Fora, Minas Gerais, Brasil. Se utilizó el Eating Attitudes Test (EAT-26) y el Major Depression Inventory (MDI) para evaluar comportamientos de riesgo en trastornos de conducta alimentaria y los sintomas depresivos, respectivamente. El modelo de regresión lineal mostró que el $18 \%$ de las puntuaciones EAT-26 fueron influenciados por $M D I(F(1,370)=14,18 ; p=0,001)$. Por otra parte, los resultados indicaron una asociación estadísticamente significativa entre los síntomas depresivos y comportamientos de riesgo para transtornos alimentarios $\left(\chi^{2}=14,71 ;\right.$ Wald $\left.=12,90 ; p=0,001\right)$. Se concluyó que los sintomas depresivos estaban relacionados con los comportamientos de riesgo para los trastornos de la conducta alimentaria en adolescentes. Por lo tanto, las niñas con algún nivel de depresión mostraron una mayor tendencia a adoptar comportamientos de riesgo, relacionados con trastornos de la conducta alimentaria como un hábito diario.

Trastornos de la Conducta Alimentaria; Depresión; Adolescente

\section{References}

1. Alves E, Vasconcelos FAG, Calvo MCM, Neves J. Prevalência de sintomas de anorexia nervosa e insatisfação com a imagem corporal em adolescentes do sexo feminino do Município de Florianópolis, Santa Catarina, Brasil. Cad Saúde Pública 2008; 24:503-12.

2. Fortes LS, Conti MA, Ferreira MEC. Relação entre comportamentos de risco para transtornos alimentares e processo maturacional em jovens atletas. Rev Bras Ativ Fís Saúde 2012; 17:383-95.

3. Schulte SJ, Thomas J. Relationship between eating pathology, body dissatisfaction and depressive symptoms among male and female adolescents in the United Arab Emirates. Eat Behav 2013; 14: 157-60.

\section{Contributors}

L. S. Fortes conducted the statistical analyses and wrote the article. J. F. Filgueiras collected the data and revised the article. M. E. C. Ferreira supervised the entire project and revised the article.

\section{Acknowledgments}

The authors wish to thank the research subjects for their voluntary participation and the Laboratory for Research on the Body at the Federal University of Juiz de Fora for lending the data collection material.
4. Knoph C, Holle AV, Zerwas S, Torgersen L, Tambs $\mathrm{K}$, Stoltenberg C, et al. Course and predictors of maternal eating disorders in the postpartum period. Int J Eat Disord 2013; 46:355-68.

5. Rodgers R, Cabrol H, Paxton SJ. An exploration of the tripartite influence model of body dissatisfaction and disordered eating among Australian and French college women. Body Image 2011; 8: 208-15.

6. Fortes LS, Almeida SS, Ferreira MEC. Processo maturacional, insatisfação corporal e comportamento alimentar inadequado em jovens atletas. Rev Nutr 2012; 5:575-86. 
7. Scherer FC, Martins CR, Pelegrini A, Matheus SC, Petroski EL. Imagem corporal em adolescentes: associação com a maturação sexual e sintomas de transtornos alimentares. J Bras Psiquiatr 2010; 59:198-202.

8. Martins CR, Pelegrini A, Matheus SC, Petroski EL. Insatisfação com a imagem corporal e a relação com estado nutricional, adiposidade corporal e sintomas de anorexia e bulimia em adolescentes. Rev Psiquiatr Rio Gd Sul 2010; 32:19-23.

9. World Health Organization. Development of a WHO growth reference for school-aged children and adolescents. Bull World Health Organ 2007; 85:660-7.

10. Gondoli DM, Corning AF, Salafia EHB, Bucchianeri MM, Fitzsimmons EE. Heterosocial involvement, peer pressure for thinness, and body dissatisfaction among young adolescent girls. Body Image 2011; 8:143-8.

11. Siervogel RM, Demerath EW, Schubert C, Remsberg KE, Chumlea WC, Sun S, et al. Puberty and body composition. Horm Res 2003; 60:36-45.

12. Miranda VPN, Conti MA, Bastos R, Ferreira MEC. Body dissatisfaction in Brazilian adolescents in small towns of Minas Gerais. J Bras Psiquiatr 2011; 60:190-7.

13. Caqueo-Urizar A, Ferrer-Garcia M, Toro J, Gutierrez-Maldonado J, Penaloza C, Cuadros-Sosa Y, et al. Associations between sociocultural pressures to be thin, body distress, and eating disorder symptomatology among Chilean adolescent girls. Body Image 2011; 8:78-81.

14. Parcias S, Rosario BP, Sakae T, Monte F, Guimarães ACA, Xavier AJ. Validação da versão em português do Inventário de Depressão Maior. J Bras Psiquiatr 2011; 60:164-70.

15. Kinyanda E, Kizza R, Abbo C, Ndyanabangi S, Levin J. Prevalence and risk factors of depression in childhood and adolescence as seen in 4 districts of north-eastern Uganda. BMC Int Health Hum Rights 2013; 13:1-10.

16. Bighetti F, Santos CB, Santos JE, Ribeiro RPP. Tradução e avaliação do Eating Attitudes Test em adolescentes do sexo feminino de Ribeirão Preto, São Paulo. J Bras Psiquiatr 2004; 53:339-46.

17. Nubila HBVD, Buchalla CM. O papel das classificações da OMS - CID e CIF nas definições de deficiência e incapacidade. Rev Bras Epidemiol 2008; 11:324-35.
18. Conti MA, Cordás TA, Latorre MRDO. Estudo de validade e confiabilidade da versão brasileira do Body Shape Questionnaire (BSQ) para adolescentes. Rev Bras Saúde Matern Infant 2009; 9:331-8.

19. Leal GVS, Philippi ST, Polacow VO, Cordás TA, Alvarenga MS. O que é comportamento de risco para transtornos alimentares em adolescentes? J Bras Psiquiatr 2013; 62:62-75.

20. Fortes LS, Amaral ACS, Almeida SS, Ferreira MEC. Efeitos de diversos fatores sobre o comportamento alimentar de adolescentes. Ciênc Saúde Coletiva 2013; 18:3301-10.

21. Almeida SS, Zanatta DP, Rezende FF. Imagem corporal, ansiedade e depressão em pacientes obesos submetidos à cirurgia bariátrica. Estud Psicol (Natal) 2012; 17:153-60.

22. Matos MIR, Aranha LS, Faria AN, Ferreira SRG, Bacaltchuck J, Zanella MT. Binge eating disorder, anxiety, depression and body image in grade III obesity patients. Rev Bras Psiquiatr 2002; 24:165-9.

23. Chen J, Li X, Natsuaki MN, Leve LD, Harold GT. Genetic and environmental influences on depressive symptoms in Chinese adolescents. Behav Genet 2014; 44:36-44.

24. Brière FN, Rohde $\mathrm{P}$, Shaw $\mathrm{H}$, Stice E. Moderators of two indicated cognitive-behavioral depression prevention approaches for adolescents in a school-based effectiveness trial. Behav Res Ther 2014; 53:55-62.

25. Durmaz Y, Alayli G, Canbaz S, Zahiroglu Y, Bilgici A, Ilhanli I, et al. Prevalence of juvenile fibromyalgia syndrome in an urban population of Turkish adolescents: impact on depressive symptoms, quality of life and school performance. Chin Med J (Engl) 2013; 126:3705-11.

26. Fortes LS, Morgado FFR, Ferreira MEC. Fatores associados ao comportamento alimentar inadequado em adolescentes escolares. Rev Psiquiatr Clín 2013; 40:59-64.

Submitted on 12/Nov/2013

Final version resubmitted on 19/May/2014

Approved on 04/Jun/2014 